Corrigendum

\title{
Corrigendum to "Golden carbon of Sargassum forests revealed as an opportunity for climate change mitigation" [Sci. Total Environ., 729 (2020) Start page - End page/ 138745]
}

Lidiane P. Gouvêa $^{\text {a,* }}$, Jorge Assis ${ }^{\text {b }}$, Carlos F.D. Gurgel ${ }^{\text {a }}$, Ester A. Serrão ${ }^{\text {b }}$, Thiago C.L. Silveira ${ }^{c}$, Rui Santos ${ }^{\text {b }}$, Carlos M. Duarte ${ }^{\mathrm{d}}$, Leticia M.C. Peres ${ }^{\mathrm{a}}$, Vanessa F. Carvalho ${ }^{\mathrm{a}}$, Manuela Batista ${ }^{\mathrm{a}}$, Eduardo Bastos ${ }^{\mathrm{a}}$, Marina N. Sissini ${ }^{\text {a }}$, Paulo A. Horta ${ }^{a}$

a Phycology Laboratory, Department of Botany, Biological Sciences Center, Federal University of Santa Catarina, Florianopolis, Santa Catarina, Brazil

b CCMAR - Centre of Marine Sciences, University of Algarve, Faro, Portugal

c Department of Ecology and Zoology, Biological Sciences Center, Federal University of Santa Catarina, Trindade, Florianopolis, Santa Catarina, Brazil

${ }^{\mathrm{d}}$ Red Sea Research Center (RSRC), Computational Bioscience Research Center (CBRC), King Abdullah University of Science and Technology, Thuwal, Saudi Arabia
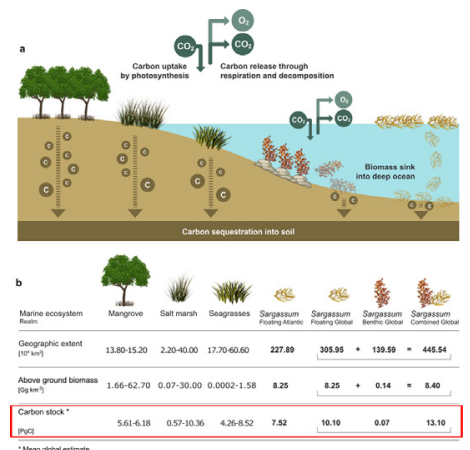

The authors regret that the printed version of the above article contained errors.

These errors in no way affect the analyses performed in this manuscript, the reported results, or the draw conclusions. The authors would like to apologise for any inconvenience caused.

The requested change does not affect the measures, because all estimation was based on raw values, without conversion to $\mathrm{Gg} \mathrm{km}^{-2}$. The correct and final version follows.

Page 3:

The final value was obtained according to the equation below:

Carbon stock in above - ground biomass $\left(\mathrm{Gg} \mathrm{km}^{-2}\right)$ : \% C X AGB X area (obtained in the Boosted Regression Trees-BRT Model)

Changes to:

Carbon stock in above-ground biomass (Pg C): \% C (dry weight) X AGB (dry weight) X area (obtained in the Boosted Regression Trees-BRT Model)

* Biomass dry weight corresponds to $10 \%$ of wet weight.

DOI of original article: https://doi.org/10.1016/j.scitotenv.2020.138745.

* Corresponding author.

E-mail address: lidi_pel@hotmail.com (L.P. Gouvêa). 
Page 4, first paragraph of Results:

“... and a potential standing stock $82.58 \mathrm{Gg} \mathrm{km}^{-2}$ of floating Sargassum in the Atlantic Ocean. At the global scale, models estimated 305.95 and $139.59 \cdot 10^{4} \mathrm{~km}^{2}$ of floating and benthic Sargassum, respectively $\left(445.54 \cdot 10^{4} \mathrm{~km}^{2}\right.$ in total), and overall biomass of $84.05 \mathrm{Gg} \mathrm{km}{ }^{-2}$, which corresponds to 13.1 Pg C globally (Fig. 1b)".

Changes to:

“....and a potential standing stock $8.25 \mathrm{Gg} \mathrm{km}^{-2}$ of floating Sargassum in the Atlantic Ocean. At the global scale, models estimated 305.95 and $139.59 \cdot 10^{4} \mathrm{~km}^{2}$ of floating and benthic Sargassum, respectively ( $445.54 \cdot 10^{4} \mathrm{~km}^{2}$ in total), and overall biomass of $8.40 \mathrm{Gg} \mathrm{km}^{-2}$, which corresponds to 13.1 Pg C globally (Fig. 1b)".

Page 4, first paragraph of Discussion:

"These floating Sargassum estimates are increased up to $25.2 \cdot 10^{3} \mathrm{Gg}$ when considering the potential global distribution of the genus (Fig. $1 \mathrm{~b}$ )".

Changes to:

"These floating Sargassum estimates are increased up to $25,241 \cdot 10^{3} \mathrm{Gg}$ when considering the potential global distribution of the genus (Fig. $1 \mathrm{~b}$ )". Changes in Fig. 1b:

Fig. 1 b

Corrections of values in Above ground biomass of $82.58 \mathrm{Gg} \mathrm{km}^{-2}, 1.47 \mathrm{Gg} \mathrm{km}^{-2}$ and $84.05 \mathrm{Gg} \mathrm{km}^{-2}$. Also, the values of mangrove, salt marsh and seagrasses were converted to $\mathrm{Gg} \mathrm{km}^{-2}$.

\section{Changes to:}

$8.25 \mathrm{Gg} \mathrm{km}^{-2}, 0.14 \mathrm{Gg} \mathrm{km}^{-2}$ and $8.40 \mathrm{Gg} \mathrm{km}^{-2}$.Fig. 1(a) Important marine ecosystems (from left to right: mangroves, saltmarshes, seagrasses and Sargassum beds). Main scheme represents carbon uptake via photosynthesis (green arrows) and subsequent long-term sequestration into biomass and soil (brown dashed arrows) or respiration (green arrows). The Sargassum biomass (floating and benthic) can sequester and transport atmospheric carbon into the deep ocean. (b) Carbon storage potential of important marine ecosystems, including Sargassum stock. Geographic extent in $\mathrm{km}^{2}\left(10^{4} \mathrm{~km}^{2}\right)$, Mean global estimate of above ground biomass $\left(\mathrm{Gg} \mathrm{km}^{-2}\right)$ and Mean global estimate of carbon stock in above ground biomass (PgC). Data obtained from Howard et al. (2017), except for above ground biomass values (Fourqurean et al., 2012; Quintana-Alcantara et al., 2014; Rovai et al., 2016; Castillo et al., 2010). The results obtained in the present study are represented in bold. (For interpretation of the references to color in this figure legend, the reader is referred to the web version of this article.)The images referring to mangrove trees, seagrasses, salt marsh, benthic and floating Sargassum were obtained from the websites: http://gratispng.com; belvil2009.blogspot.com and atricolinabiologa.blogspot.com.

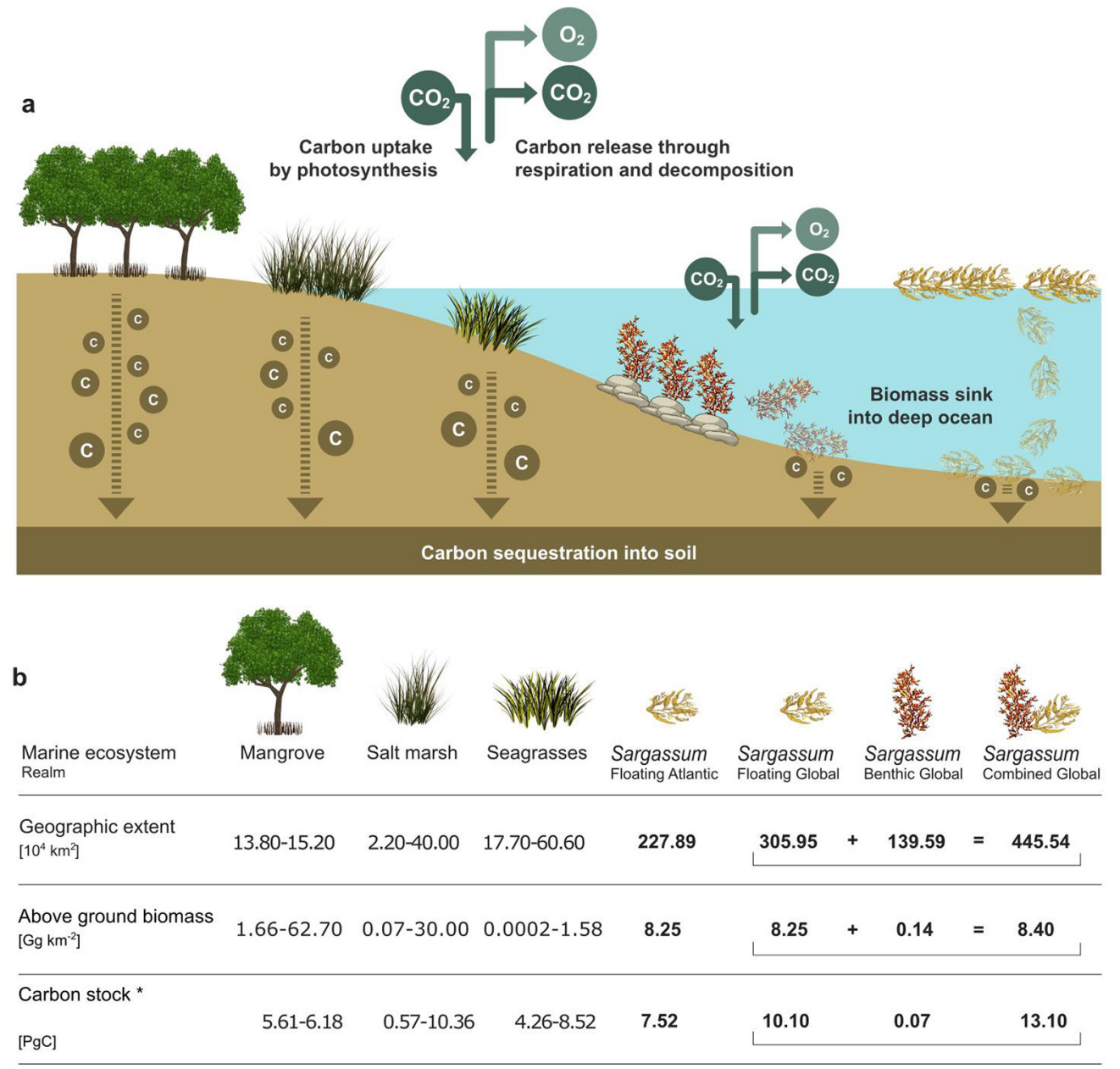

* Mean global estimate

We include a reference in the Fig. 1 legend:

Castillo, J. M., Rubio-Casal, A. E., Figueroa, E. 2010. Cordgrass biomass in coastal marshes. Biomass, 1-26. 
Table S4 (Supplementary material):

Note: The table S4 includes biomass data (wet weight) at peak events (Sissini et al., 2017 and this study)

Correction of value : 14000 g.m $\mathrm{m}^{-2}$ instead of 140000 g.m $\mathrm{m}^{-2}$

We included three references in Table S4:

Stoner, A. W. 1983. Pelagic Sargassum: Evidence for a major decrease in biomass. Deep Sea Research Part A. Oceanographic Research Papers, 30(4), 469-474.

Butler, J. N., Morris, B. F., Sass, J. 1973. Pelagic Tar from Bermuda and the Sargasso Sea (No. BBS-10). Bermuda Biological Station for Research St George's West.

Schell, J. M., Goodwin, D. S., Siuda, A. N. 2015. Recent Sargassum inundation events in the Caribbean: shipboard observations reveal dominance of a previously rare form. Oceanography, 28(3), 8-11. 